CONEIDERYMA

UNCLASSIFIED

by

Arthur A. Bauer

Glen H. Beatty

Frank A. Rough

Ronald F. Dickerson

\author{
Contract No. W-7405-eng -92 \\ THE CONSTITUTION OF ZIRCONIUM-URANIUM ALLOYS \\ CONTAINING OXYGEN OR NITROGEN

然

Report No. BMI-1187

C-25 Metallurgy and Ceramics $(\mathrm{M}-3679,19$ th Ed.) 


\section{DISCLAIMER}

This report was prepared as an account of work sponsored by an agency of the United States Government. Neither the United States Government nor any agency Thereof, nor any of their employees, makes any warranty, express or implied, or assumes any legal liability or responsibility for the accuracy, completeness, or usefulness of any information, apparatus, product, or process disclosed, or represents that its use would not infringe privately owned rights. Reference herein to any specific commercial product, process, or service by trade name, trademark, manufacturer, or otherwise does not necessarily constitute or imply its endorsement, recommendation, or favoring by the United States Government or any agency thereof. The views and opinions of authors expressed herein do not necessarily state or reflect those of the United States Government or any agency thereof. 


\section{DISCLAIMER}

Portions of this document may be illegible in electronic image products. Images are produced from the best available original document. 


\section{3 and 4}

TABLE OF CONTENTS

$\underline{\text { Page }}$

INTRODUCTION

EXPERIMENTAL TECHNIQUES AND ANALYSIS

Alloy and Specimen Preparation . . . . . . . . . . . . . . . 8 Metallography and Quantitative Lineal Analysis. . . . . . . . . . 8

Mathematical Assumptions and Equations . . . . . . . . . . . . . 9

EXPERIMENTAL RESULTS . . . . . . . . . . . . . . . . . . 12

Metallographic and Quantitative Lineal Data . . . . . . . . . . 12

Calculations . . . . . . . . . . . . . . . . . . . . . 16

Variation in Constitution With Oxygen Content . . . . . . . . . . . 19

SUMMARY AND CONCLUSIONS . . . . . . . . . . . . . . . . . . . . 21

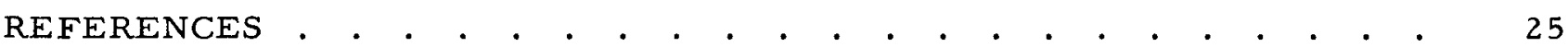




\title{
THE CONSTITUTION OF ZIRCONIUM-URANIUM ALLOYS CONTAINING OXYGEN OR NITROGEN
}

\author{
Arthur A. Bauer, Glen H. Beatty \\ Frank A. Rough, and Ronald F. Dickerson
}

\begin{abstract}
The extent of the alpha-plus-beta-zirconium region in the binary zirconiumuranium system at $660 \mathrm{C}$ has been determined. The phase boundary occurs at $31 \mathrm{w} / \mathrm{o}$ uranium. This determination is based upon a quantitative study of zirconium-uranium alloys containing oxygen and nitrogen; the data were employed in extrapolating to zero oxygen and nitrogen content in order to determine the constitution of binary alloys.
\end{abstract}

On the basis of the data obtained, revisions in the constitutional diagrams of the zirconium-uranium and zirconium-uranium-oxygen systems are proposed. A partial zirconium-uranium-nitrogen diagram is presented.

\section{INTRODUCTION}

As a result of recent studies $(1)$, the constitution of the zirconium-uranium system has been fairly well defined. A diagram for the system is shown in Figure 1. However, both oxygen and nitrogen are known $(1,2,3)$ to have a pronounced effect on the limits of both the beta- and epsilon-phase regions. It has been shown that small amounts of oxygen severely constrict the compositional limits of the se phase regions in the ternary zirconium-uranium-oxygen system. A previously published tentative diagram (3) shown in Figure 2 illustrates the beta-phase constriction resulting from oxygen additions.

Generally, iodide zirconium has been used in constitutional studies of zirconiumuranium alloys. While this is the highest purity material available, cast iodide zirconium-uranium alloys will generally average from 200 to $300 \mathrm{ppm}$ oxygen and from 50 to $60 \mathrm{ppm}$ nitrogen. Thus, while the constitution of the zirconium-uranium system is fairly well defined, it must be realized that this definition applies to alloys containing in the vicinity of $250 \mathrm{ppm}$ oxygen and $50 \mathrm{ppm}$ nitrogen.

The present investigation was undertaken to accurately determine the boundary between the alpha plus beta and beta phases at a single temperature in the binary zirconium-uranium system by quantitatively determining the effects of oxygen and nitrogen on this boundary.

\section{EXPERIMENTAL TECHNIQUES AND ANALYSIS}

Alloys containing 22 to $70 \mathrm{w} / 0$ uranium and controlled additions of oxygen and nitrogen were prepared. Specimens were heat treated at $660 \mathrm{C}$ and subjected to quantitative lineal analysis.

(1) References appear at end of report. 


\section{CONFIDENTIAL}

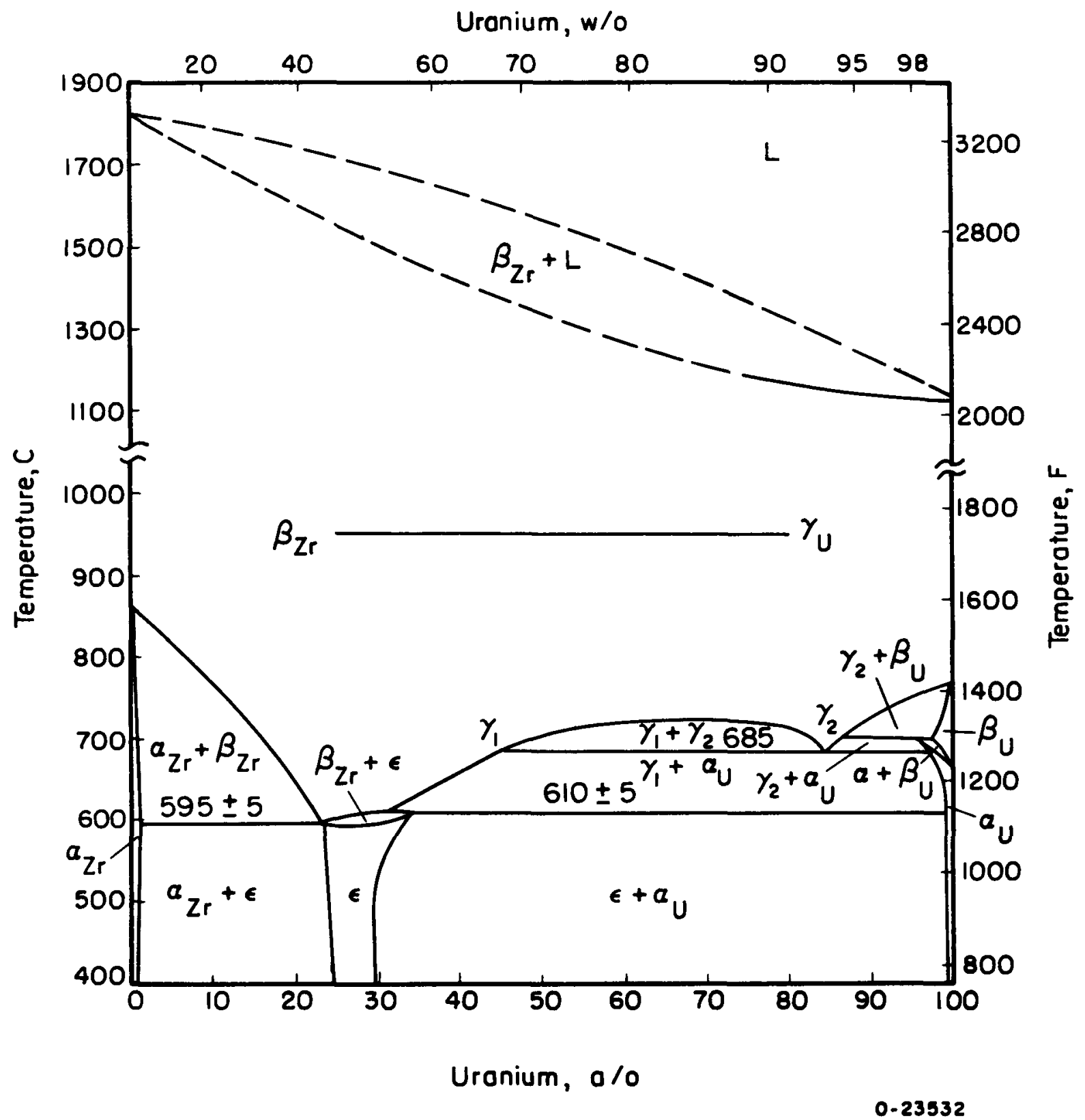

FIGURE 1. THE ZIRCONIUM-URANIUM CONSTITUTIONAL DIAGRAM 

8

An analysis of the requirements for mathematical treatment of the quantitative data obtained to define the alpha-plus-beta-zirconium region of the ternary zirconiumuranium-oxygen and nitrogen systems was made. Equations of a suitable form for insertion in an IBM 650 computer were developed.

\section{Alloy and Specimen Preparation}

Alloys containing $22,40,50,60$, and 70 w/o uranium were prepared from biscuit uranium and zirconium of three different oxygen levels: crystal-bar zirconium containing about $50 \mathrm{ppm}$ oxygen; normal sponge zirconium containing about $1000 \mathrm{ppm}$ oxygen; and sponge zirconium to which oxygen was added in a modified Sieverts apparatus to bring its oxygen level to about $3000 \mathrm{ppm}$. The alloys were double arc melted by consumable-electrode arc-melting techniques.

Alloys of 22,40 , and $45 \mathrm{w} / \mathrm{o}$ uranium containing greater amounts of oxygen were arc melted by tungsten-electrode techniques from biscuit uranium, iodide zirconium, and iodide zirconium to which $10,000 \mathrm{ppm}$ oxygen was added. The oxygen was added in a modified Sieverts apparatus.

Alloys of 22 and $40 \mathrm{w} / \mathrm{o}$ uranium containing nitrogen were similarly prepared. However, the nitrogen was initially added to iodide zirconium by arc melting it under a nitrogen atmosphere.

The final castings were forged and rolled at temperatures between 790 and $840 \mathrm{C}$ to 1/2- and 1/4-in. rod. Specimens were cut off for heat treatment, chemical analysis, and vacuum-fusion analysis. All specimens were pickled to remove evidence of surface contamination. Chemical analyses indicated that the intended uranium compositions had been achieved within $\pm 0.5 \mathrm{w} / \mathrm{o}$ uranium. Consequently, nominal compositions are employed throughout this report. The nitrogen content, by analysis, was from 40 to 70 $\mathrm{ppm}$ in the alloys containing various amounts of oxygen. Other nitrogen and oxygen analyses are tabulated in later sections of this report. Oxygen contents were determined by vacuum-fusion analysis.

All specimens for study were heat treated for $100 \mathrm{hr}$ at $660 \mathrm{C}$ and water quenched. Heat treatments were performed in a vacuum furnace under a pressure of $5 \times 10^{-5} \mathrm{~mm}$ mercury or less.

\section{Metallography and Quantitative Lineal Analysis}

After heat treatment, specimens were mounted in bakelite, ground wet through 600-grit paper, and polished on Forstmann's cloth with Linde B as the abrasive. The specimens were etched with a mixture consisting of $30 \mathrm{~cm}^{3}$ lactic acid, $30 \mathrm{~cm}^{3}$ nitric acid, and 6 to 10 drops of hydrofluoric acid.

Quantitative lineal measurements were obtained by using a Hurlbut counter. From four to eight traverses were made on a single specimen surface. The areas for 
measurement were randomly selected. All measurements were confined to the centers of the specimens because a small amount of surface contamination was evident.

Specimens prepared from zirconium containing 50, 1000, and 3000 ppm oxygen and containing 50, 60, and $70 \mathrm{w} / \mathrm{o}$ uranium were examined metallographically. Information on the uranium-rich limit of the boundary between the beta phase and alpha-plus-beta phase was sought.

\section{Mathematical Assumptions and Equations}

The quantitative treatment of a two-phase ternary section is very similar to that applied to a two-phase region in a binary system. Complications are introduced by the fact that the phases in equilibrium in a series of binary alloys, heat treated at the same temperature, are of the same composition, whereas in a ternary system randomly selected alloys will have compositions that fall on different tie lines and, consequently, the composition of the equilibrium phases will vary. Thus, while analysis of a single composition is theoretically sufficient to determine the phase boundaries in a binary system at a single temperature, analysis of a minimum of two compositions is required for determination of a single boundary in a ternary system, assuming that the remaining boundaries of the two-phase region have been defined.

In order to analyze the quantitative data obtained, the following assumptions concerning the nature of the two-phase alpha-plus-beta region of the ternary zirconiumuranium-oxygen and-nitrogen systems were made:

(1) The phase region can be represented as a regular quadrilateral with no curvature to any sides.

(2) The tie lines connecting the alpha- and beta-zirconium phases in equilibrium move up from zero oxygen content in such a manner that the ratio of oxygen or nitrogen in the beta and alpha phases remains constant. This ratio is defined by the phase boundary between the alpha-plus betazirconium region and the region containing alpha-plus-beta zirconium and alpha uranium.

(3) The uranium content of the alpha-zirconium phase remains constant at $0.5 \mathrm{w} / \mathrm{o}$; neither oxygen nor nitrogen affect this solubility.

The assumed geometry of the phase region is shown in Figure 3, from which an expression for phase limits in terms of composition has been derived as follows:

$$
\mathrm{BD} / \mathrm{DE}=\mathrm{CF} / \mathrm{AG} ; \mathrm{BD}=\frac{\mathrm{CF}}{\mathrm{AG}} \mathrm{DE}
$$




\section{CONFIDENTIAL}

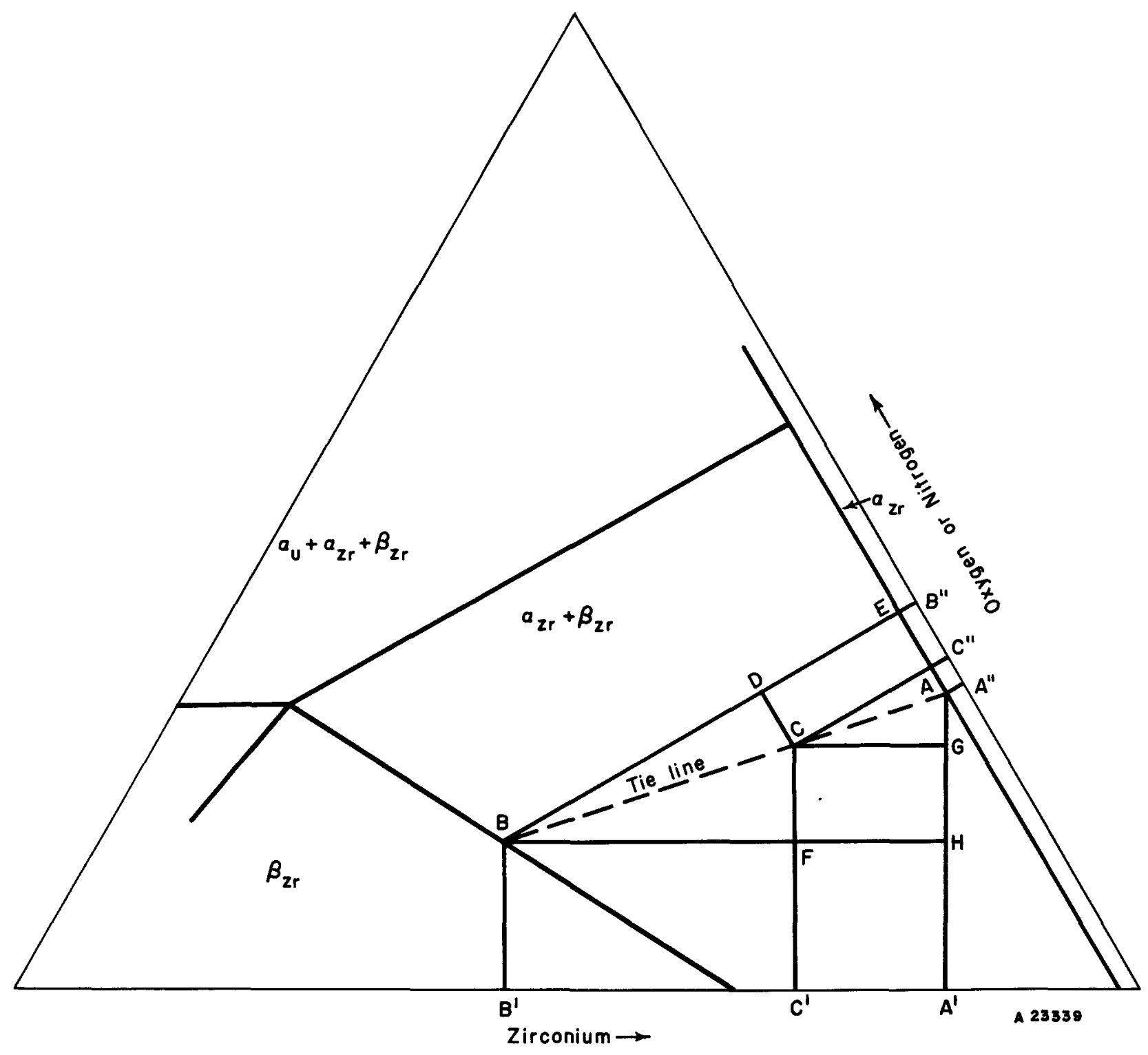

FIGURE 3. GEOMETRICAL REPRESENTATION OF ALPHA-PLUS-BETAZIRCONIUM REGION IN TERNARY SYSTEMS

CONFIDENTIAL 


\section{CONFIDENTIAL}

11

$$
\begin{gathered}
C F=C C^{\prime}-B B^{\prime} \\
A G=A A^{\prime}-C C^{\prime} \\
D E=C C^{\prime \prime}-E B^{\prime \prime} \\
B B^{\prime \prime}=C C^{\prime \prime}+B D=C C^{\prime \prime}+\frac{\left(C C^{\prime \prime}-E B^{\prime \prime}\right)\left(C C^{\prime}-B B^{\prime}\right)}{\left(A A^{\prime}-C C^{\prime}\right)}
\end{gathered}
$$

Therefore

$$
U_{B}=U_{C}+\frac{\left(U_{C}-U_{A}\right)\left(G_{C}-G_{B}\right)}{\left(G_{A}-G_{C}\right)}
$$

where

$$
\begin{aligned}
& U_{B}=B B^{\prime \prime}=\text { uranium content of equilibrium beta phase } \\
& U_{C}=C C^{\prime \prime}=\text { uranium content of analyzed specimen } \\
& U_{A}=E B^{\prime \prime}=\text { uranium content of equilibrium alpha phase } \\
& G_{C}=C C^{\prime}=\text { gas content of analyzed specimen } \\
& G_{B}=B B^{\prime}=\text { gas content of equilibrium beta phase } \\
& G_{A}=A A^{\prime}=\text { gas content of equilibrium alpha phase. }
\end{aligned}
$$

Since the quantitative data are obtained in the form of volume percentages a conversion to weight percentages of the alpha and beta phases is required. This is accomplished by the following equations:

$$
w / o \alpha=\frac{100(v / o \alpha)(\rho \alpha)}{(v / o \alpha)(\rho \alpha)+(v / o \beta)(\rho \beta)}
$$

and

$$
w / \circ \beta=\frac{100(v / o \beta)(\rho \beta)}{(v / \circ \alpha)(\rho \alpha)+(v / \circ \beta)(\rho \beta)}
$$

where $w / o, v / o$, and $\rho$ refer to the weight percentages, volume percentages, and densities of the alpha and beta phases.

The gas contents of the alpha and beta phases were determined from the equation:

$$
G_{B}=\frac{100 G_{C}}{k(w / o \alpha)+(w / o \beta)},
$$

where

$$
\mathrm{k}=\frac{\mathrm{G}_{\mathrm{A}}}{\mathrm{G}_{\mathrm{B}}} \text {, }
$$

the ratio between the gas content of the alpha and beta phases. This ratio follows from the second assumption made in the analysis. 


\section{CONFIDENTIAL}

12

The order in which the equations are employed in treating experimental data are $(2),(3),(4),(5)$, and (1). Values for the densities of the alpha and beta phases were taken from experimental
data. 4,5$)$ For computer application, equations were fitted to the curves of change in density with composition. For the beta phase, the equation developed was

$$
\rho_{\beta}=6.5352706+0.041150252 \mathrm{U}_{\mathrm{B}}+0.0001893009 \mathrm{U}_{\mathrm{B}}^{2}+0.0000044419833 \mathrm{U}_{\mathrm{B}}^{3} .
$$

The density of the alpha phase was treated over two ranges of oxygen content.

For

$$
\mathrm{G}_{\mathrm{A}}<1.8, \rho_{\alpha}=6.5400+0.0160430 \mathrm{G}_{\mathrm{A}}+0.0114577 \mathrm{G}_{\mathrm{A}}^{2},
$$

and for

$$
\mathrm{G}_{\mathrm{A}} \geq 1.8, \rho_{\alpha}=6.503+0.05706 \mathrm{G}_{\mathrm{A}} \text {. }
$$

These equations are based upon data for the zirconium-oxygen system. Since similar data were not available for zirconium-nitrogen alloys, it was assumed that, with small error, these equations were applicable to their treatment in view of the similarity of the effects of oxygen and nitrogen on zirconium.

It is seen that in this analysis, the following are known: $U_{A}$, the uranium content of the alpha phase, $0.5 \mathrm{w} / 0$ uranium; $\mathrm{U}_{\mathrm{C}}$ and $\mathrm{G}_{\mathrm{C}}$, the uranium and oxygen or nitrogen contents, respectively, of the specimen submitted to quantative lineal analysis; $v / o \alpha$ and $\mathrm{v} / \mathrm{o} \beta$, the measured volume percentages of the alpha and beta phases, respectively, $\rho_{\alpha}$ and $\rho_{\beta}$, the densities of the alpha and beta phases in the form of the equations given previously; and $k$, the ratio of gas contents in the alpha and beta phases, respectively. The value for $\mathbf{k}$ was selected as 45 and was based upon additional metallographic studies following initial mathematical analysis of the experimental data.

Thus, five basic equations are necessary for solution of the five following unknown quantities: $U_{B}$ and $G_{B}$, the uranium and gas content of the beta phase; $G_{A}$, the gas content of the alpha phase; and w/o $\alpha$ and $w / o \beta$, the weight percentages of the alpha and beta phases present at equilibrium.

\section{EXPERIMENTAL RESULTS}

\section{Metallographic and Quantitative Lineal Data}

The results of quantitative lineal measurements are tabulated in Table 1. Typical microstructures in Figure 4 show the variation in the amount of alpha phase in zirconium $-40 \mathrm{w} / \mathrm{o}$ uranium alloys as the oxygen and nitrogen contents change.

In addition to the se data, a series of alloys containing 50,60, and $70 \mathrm{w} / \mathrm{o}$ uranium prepared from zirconium with oxygen levels of approximately 50, 1000, and $3000 \mathrm{ppm}$

CONFIDENTIAL

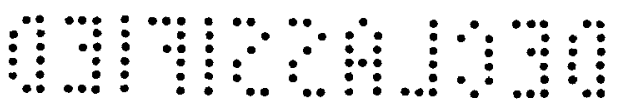


CONFIDENTIAL

13

TABLE 1. QUANTITATIVE LINEAL DATA ON ZIRCONIUM-URANIUM ALLOYS

\begin{tabular}{|c|c|c|c|c|c|}
\hline \multirow[b]{2}{*}{ Alloy } & \multirow{2}{*}{$\frac{}{\mathrm{U}_{\mathrm{C}}}$} & \multicolumn{2}{|c|}{ Composition, w/o } & \multicolumn{2}{|c|}{$\begin{array}{l}\text { Volume Percentage } \\
(\mathrm{v} / \mathrm{o}) \text { of } \alpha \text { and } \beta\end{array}$} \\
\hline & & Oxygen $(a)$ & Nitrogen(b) & $a$ & $\beta$ \\
\hline $0-1$ & 22 & 0.0227 & -- & $\begin{array}{l}44.48 \\
46.01 \\
43.55 \\
44.01\end{array}$ & $\begin{array}{l}55.52 \\
53.99 \\
56.45 \\
55.99\end{array}$ \\
\hline $\mathrm{O}-2$ & 22 & 0.0910 & -- & $\begin{array}{l}46.76 \\
45.61 \\
42.97 \\
46.94 \\
46.33 \\
42.09\end{array}$ & $\begin{array}{l}53.24 \\
54.39 \\
57.03 \\
53.06 \\
53.67 \\
57.91\end{array}$ \\
\hline$O-3$ & 22 & 0.2610 & -- & $\begin{array}{l}46.35 \\
47.95 \\
49.70 \\
50.41\end{array}$ & $\begin{array}{l}53.65 \\
52.05 \\
50.30 \\
49.59\end{array}$ \\
\hline $0-7$ & 22 & 0.7670 & -- & $\begin{array}{l}65.00 \\
65.00 \\
65.00 \\
68.00\end{array}$ & $\begin{array}{r}35.00 \\
.35 .00 \\
35.00 \\
32.00\end{array}$ \\
\hline $\mathrm{O}-4$ & 40 & 0.0286 & -- & $\begin{array}{l}3.15 \\
2.47 \\
3.22 \\
2.65\end{array}$ & $\begin{array}{l}96.85 \\
97.53 \\
96.78 \\
97.35\end{array}$ \\
\hline$O-5$ & 40 & 0.0782 & -- & $\begin{array}{r}11.05 \\
11.11 \\
10.96 \\
9.79\end{array}$ & $\begin{array}{l}88.95 \\
88.89 \\
89.04 \\
90.21\end{array}$ \\
\hline $0-6$ & 40 & 0.2000 & -- & $\begin{array}{l}21.08 \\
17.20 \\
20.78 \\
18.13 \\
22.65 \\
19.47 \\
18.62 \\
24.92\end{array}$ & $\begin{array}{l}78.92 \\
82.80 \\
79.22 \\
81.87 \\
77.35 \\
80.53 \\
81.38 \\
75.08\end{array}$ \\
\hline
\end{tabular}


CONFIDENTIAL

14

TABLE 1. (Continued)

\begin{tabular}{|c|c|c|c|c|c|}
\hline \multirow[b]{3}{*}{ Alloy } & \multicolumn{3}{|c|}{ Composition, w/o } & \multirow{2}{*}{\multicolumn{2}{|c|}{$\begin{array}{c}\text { Volume Percentage } \\
(\mathrm{v} / \mathrm{o}) \text { of } \alpha \text { and } \beta\end{array}$}} \\
\hline & \multirow{2}{*}{$\frac{\overline{U C}}{\text { Uranium }}$} & \multicolumn{2}{|c|}{$\mathrm{GC}$} & & \\
\hline & & Oxygen $(a)$ & Nitrogen $(b)$ & $\alpha$ & $\beta$ \\
\hline \multirow[t]{3}{*}{$0-8$} & 40 & 0.4560 & -- & $\begin{array}{l}32.00 \\
36.00\end{array}$ & $\begin{array}{l}68.00 \\
64.00\end{array}$ \\
\hline & & & & 31.00 & 69.00 \\
\hline & & & & 37.00 & 63.00 \\
\hline \multirow[t]{4}{*}{$0-9$} & 40 & 0.5690 & -- & 42.00 & 58.00 \\
\hline & & & & 38.00 & 62.00 \\
\hline & & & & 37.00 & 63.00 \\
\hline & & & & 40.00 & 60.00 \\
\hline \multirow[t]{4}{*}{$0-10$} & 45 & 0.5460 & -- & 33.00 & 67.00 \\
\hline & & & & 35.00 & 65.00 \\
\hline & & & & 36.00 & 64.00 \\
\hline & & & & 36.00 & 64.00 \\
\hline \multirow[t]{5}{*}{$N-1$} & 22 & -- & 0.2025 & 53.30 & 46.70 \\
\hline & & & & 51.10 & 48.90 \\
\hline & & & & 51.90 & 48.10 \\
\hline & & & & 51.10 & 48.90 \\
\hline & & & & 51.80 & 48.20 \\
\hline \multirow[t]{4}{*}{$N-2$} & 22 & -- & 0.3800 & 59.00 & 41.00 \\
\hline & & & & 59.00 & 41.00 \\
\hline & & & & 57.00 & 43.00 \\
\hline & & & & 60.00 & 40.00 \\
\hline \multirow[t]{5}{*}{$N-3$} & 40 & -- & 0.1215 & 17.90 & 82.10 \\
\hline & & & & 19.80 & 80.20 \\
\hline & & & & 16.70 & 83.30 \\
\hline & & & & 17.80 & 82.20 \\
\hline & & & & 19.70 & 80.30 \\
\hline \multirow[t]{5}{*}{$N-4$} & 40 & -- & 0.2430 & 29.90 & 70.10 \\
\hline & & & & 31.00 & 69.00 \\
\hline & & & & 27.00 & 73.00 \\
\hline & & & & 25.60 & 74.40 \\
\hline & & & & 27.90 & 72.10 \\
\hline
\end{tabular}

(a) Average nitrogen content of oxygen-containing alloys was $60 \mathrm{ppm}$.

(b) Average oxygen content of nitrogen-containing alloys was $250 \mathrm{ppm}$. 


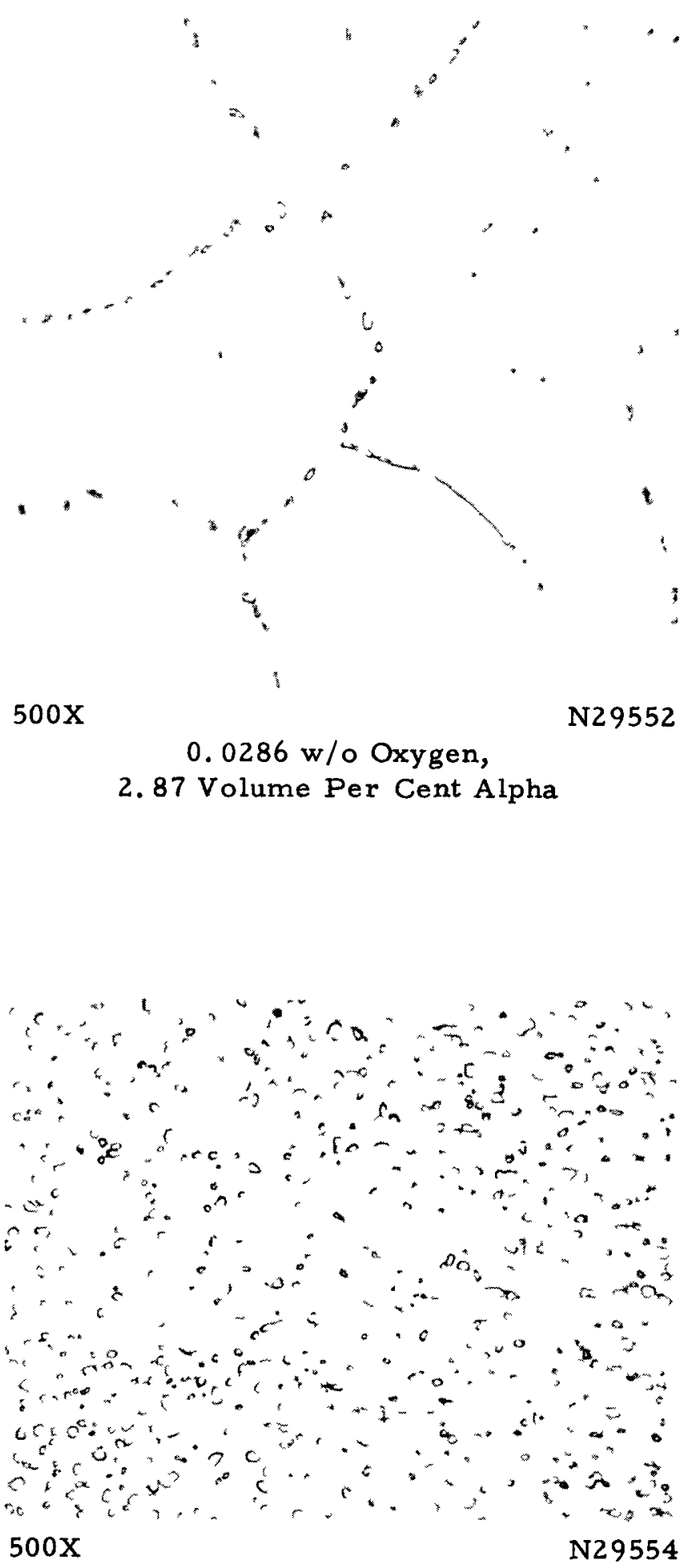

$0.2000 \mathrm{w} / 0$ Oxygen,

20.34 Volume Per Cent Alpha

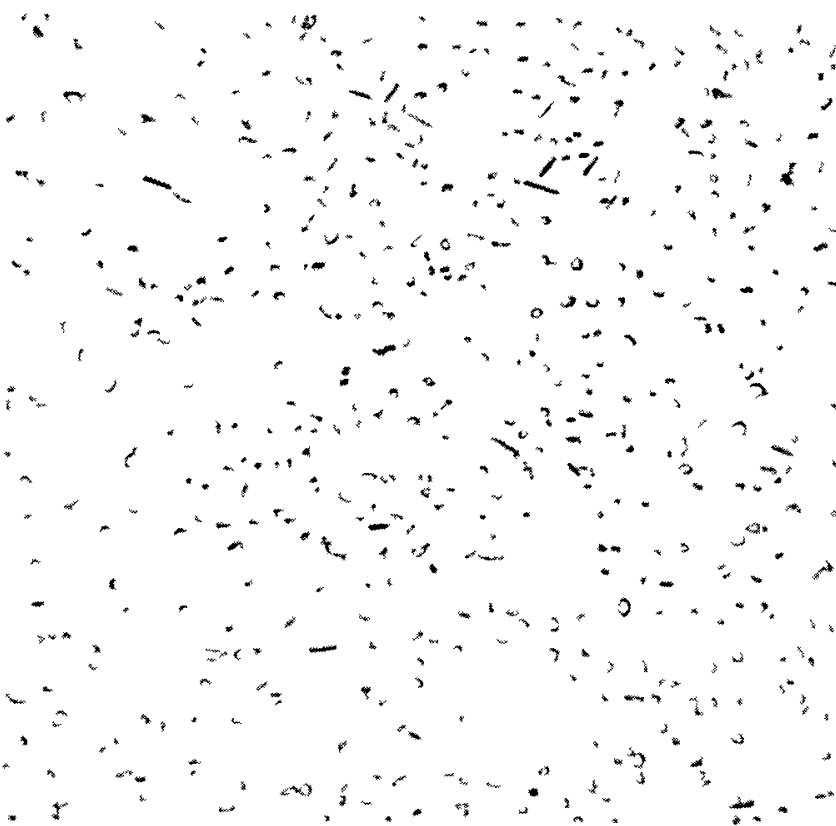

$500 \mathrm{X}$

N29553

0.0782 w/o Oxygen, 10.95 Volume Per Cent Alpha

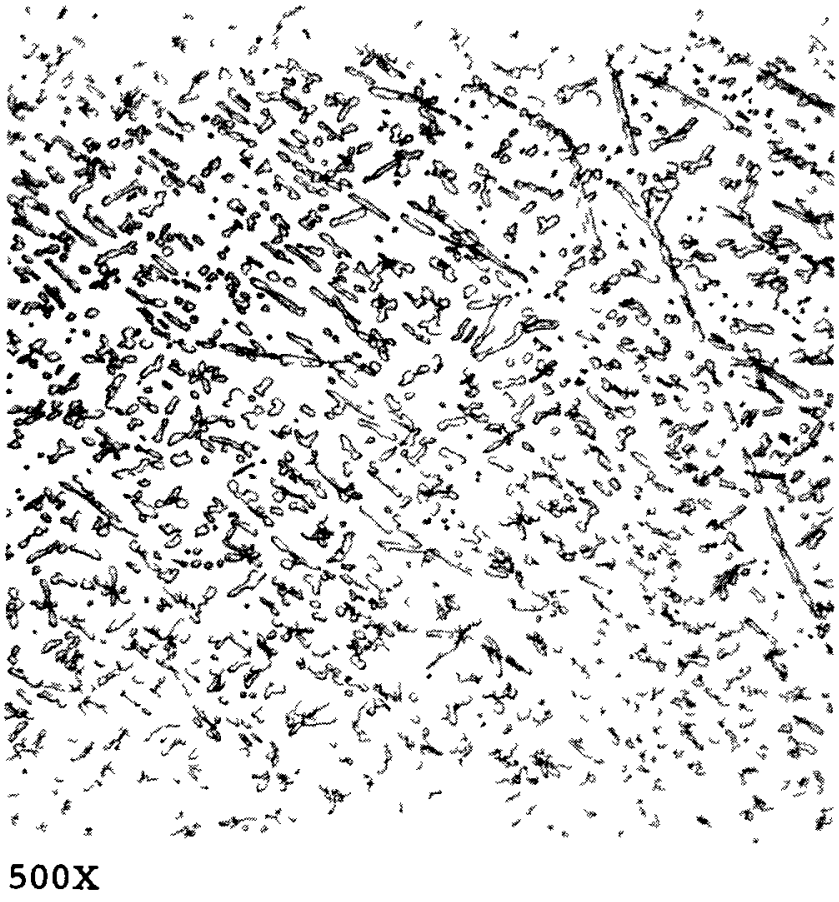

$0.2430 \mathrm{w} / \mathrm{o}$ Nitrogen,

28. 28 Volume Per Cent Alpha

FIGURE 4. MICROSTRUCTURES OF ZIRCONIUM -40 w/o URANIUM ALLOYS CONTAINING OXYGEN AND NITROGEN 
were examined metallographically. The oxygen contents of the alloys prepared averaged about 250,500 , and 1400 ppm oxygen. From these alloys, it was established that only in the $70 \mathrm{w} / 0$ uranium alloys was alpha uranium present at $660 \mathrm{C}$. Also, the $70 \mathrm{w} / \mathrm{o}$ uranium alloy was two phase when the oxygen content was $500 \mathrm{ppm}$ or less while when the oxygen content was $1400 \mathrm{ppm}$ a fairly large amount of alpha zirconium was present. The 50 and $60 \mathrm{w} / 0$ alloys had small amounts of alpha zirconium present when the oxygen content was $500 \mathrm{ppm}$, the amount of alpha zirconium increasing noticeably when the oxygen level increased to $1400 \mathrm{ppm}$.

From the se observations, it was estimated that maximum oxygen solubility at $660 \mathrm{C}$ in the beta phase was between 500 and $600 \mathrm{ppm}$ and occurred at a composition of approximately $65 \mathrm{w} / \mathrm{o}$ uranium.

\section{Calculations}

The results of the calculations are plotted in Figures 5 and 6 . Each quantitative lineal determination was treated separately; there are 46 data points on the oxygen ternary plot and 19 data points on the nitrogen ternary plot. The curves drawn through the data points were calculated from the data themselves. The equations for the curves are

$$
\begin{aligned}
& G_{B}=0.001643 U_{B}-0.05121 \text { for the zirconium-uranium-oxygen system } \\
& G_{B}=0.001230 U_{B}-0.03748 \text { for the zirconium-uranium-nitrogen system. }
\end{aligned}
$$

Employing these equations to calculate the phase limits in the binary system between the beta and alpha-plus -beta phase regions, composition limits of 31.2 and $30.5 \mathrm{w} / 0$ uranium, respectively, are obtained. A weighted average value of $31 \mathrm{w} / \mathrm{o}$ uranium is further calculated.

In making the calculations, a series of approximations was made in arriving at the final values shown. Thus, initial estimates of the densities of the alpha and beta phases were made. From these initial values, oxygen and uranium contents of the se phases were calculated, the calculated contents serving as the basis for a reselection of the densities. After three or four such approximations, no variation in the fifth significant figure of calculated compositional values was observed. The program for the IBM 650 was devised to provide the feedback of information necessary for the successive approximations.

Since the alloys studied were not true ternary alloys, both oxygen and nitrogen being present in addition to the zirconium and uranium, an additional estimate of the effect of the base levels of nitrogen and oxygen in the alloys containing varying amounts of oxygen and nitrogen was made. The estimate was based on examination of the raw quantitative data, which show that the volume percentage of alpha in a zirconium-40 w/o uranium alloy containing $2000 \mathrm{ppm}$ of oxygen averages 18.4, while the volume percentage of alpha in the zirconium $-40 \mathrm{w} / \mathrm{o}$ uranium alloy containing $1215 \mathrm{ppm}$ nitrogen averages 20.4. Thus, since both oxygen and nitrogen have the same constricting effect on the beta phase, $1200 \mathrm{ppm}$ nitrogen produces an effect roughly equivalent to $2000 \mathrm{ppm}$ of oxyger, or, oxygen is $3 / 5$ as effective as nitrogen in producing beta-phase constriction.

CONFIDENTIAL 


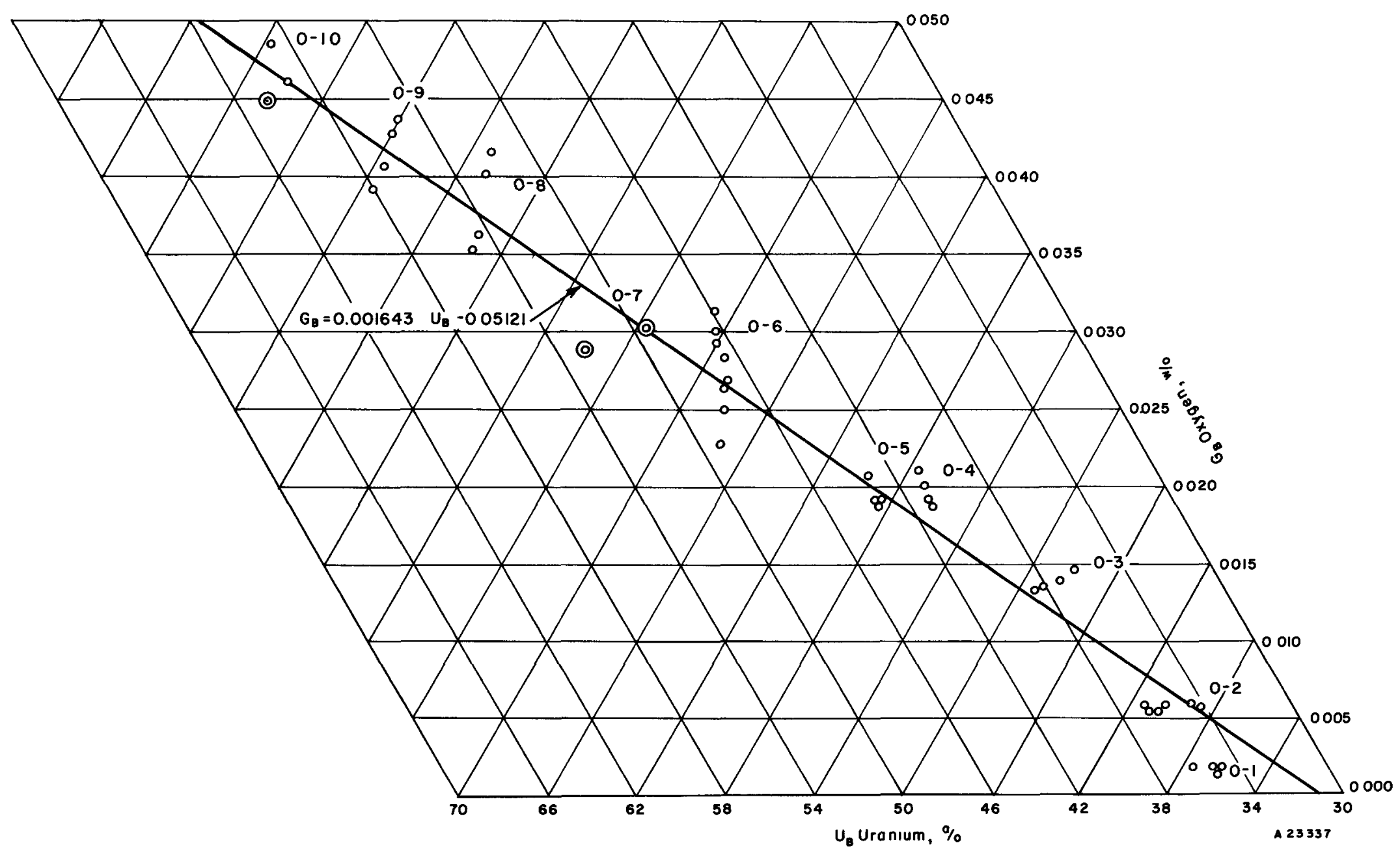

FIGURE 5. CALCULATED EXPERIMENTAL DATA POINTS FOR ZIRCONIUM-URANIUM-OXYGEN ALLOYS 
$\therefore: \cdots:$

$\therefore$

.....

م...:.:

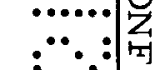

$\because$ :

…:.

:......

$\because . .$.

:...

:...:.:

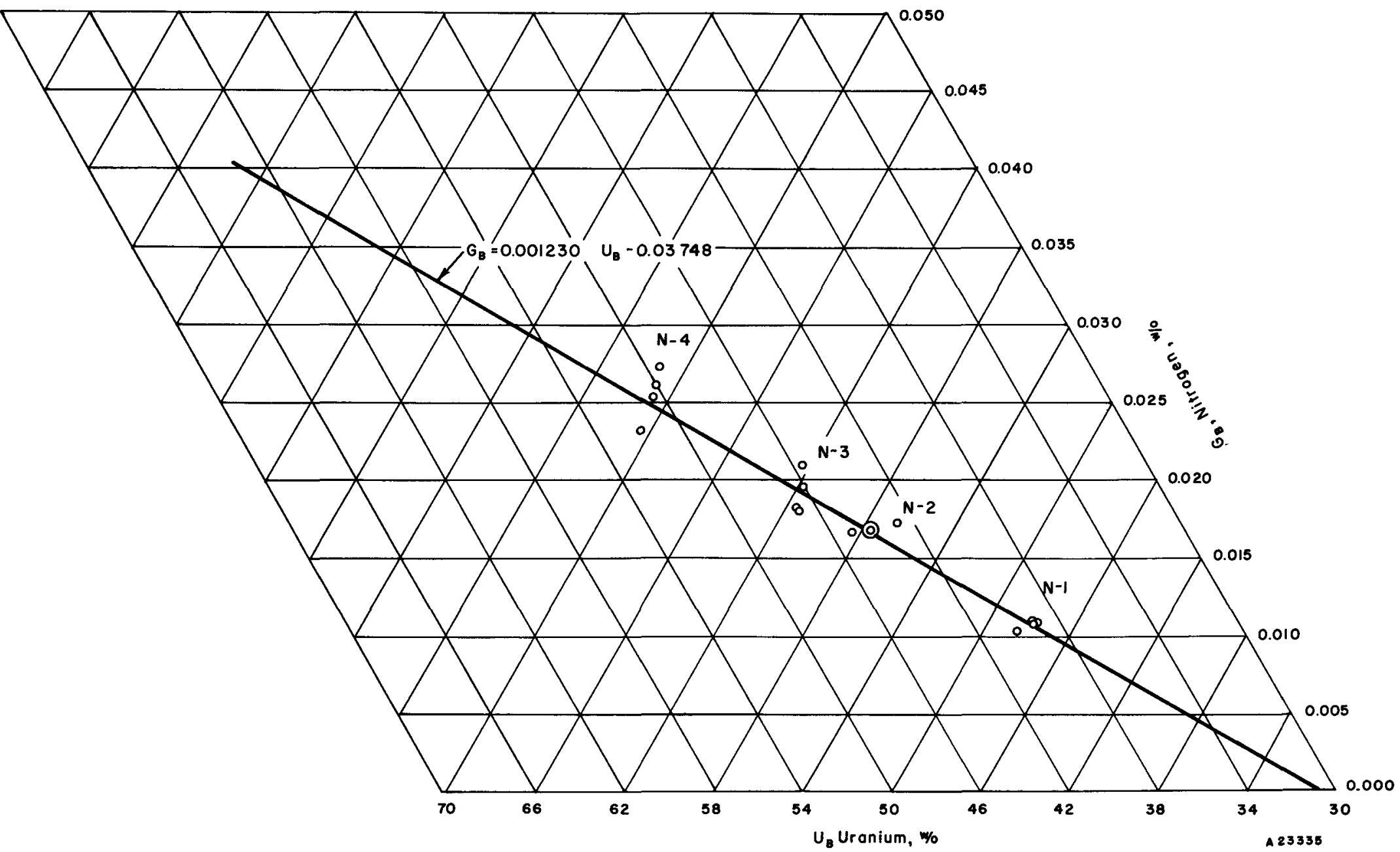

FIGURE 6. CALCULATED EXPERIMENTAL DATA POINTS FOR ZIRCONIUM-URANIUM-NITROGEN ALLOYS 
Consequently, an adjustment in the oxygen and nitrogen levels of the alloys was made in an attempt to place the alloys on a ternary basis. Since the base levels of oxygen and nitrogen were 250 and $60 \mathrm{ppm}$ respectively, an addition of $150 \mathrm{ppm}$ to the measured nitrogen levels was made in order to compensate for the base-level oxygen contamination. An addition of $100 \mathrm{ppm}$ to the measured oxygen levels was made in order to compensate for the base-level nitrogen contamination. The effect of possible interaction between oxygen and nitrogen has not been considered.

In the se calculations, as indicated earlier, a value of $k=45$ was employed for the ratio of oxygen or nitrogen between the alpha and beta phases. Ratios of 40 to 90 were investigated, the principal effect of changes in ratio being to produce a change in slope of the beta versus alpha-plus-beta phase boundary. Thus this ratio has no effect on the extrapolated value for the phase boundary in the binary system. The value of $k=45$ is found to provide a satisfactory value for the maximum oxygen solubility in the beta phase. This value is calculated to be $556 \mathrm{ppm}$ oxygen at a composition of $65 \mathrm{w} / \mathrm{o}$ uranium, which is in agreement with the metallographic observations reported on the 50,60 , and $70 \mathrm{w} / \mathrm{o}$ uranium alloys.

On the basis of this value, the oxygen content of the alpha-zirconium phase existing in equilibrium with beta containing $556 \mathrm{ppm}$ oxygen is calculated to be $25,020 \mathrm{ppm}$. Again, this value is relatively insensitive to choice of a value for $k$.

For nitrogen, maximum solubility in the beta phase is $425 \mathrm{ppm}$. Nitrogen content of the alpha phase in equilibrium with the $65 \mathrm{w} / 0$ uranium beta phase of this nitrogen composition is $19,125 \mathrm{ppm}$.

\section{Variation in Constitution With Oxygen Content}

The calculated phase boundary has been employed in preparing a series of curves showing the volume percentage of alpha phase as a function of oxygen and uranium content at $660 \mathrm{C}$ in zirconium-uranium alpha-plus-beta-phase alloys. These curves are shown in Figure 7.

The pronounced effect of oxygen on constitution is apparent from these curves. A binary zirconium -35 w/o uranium alloy is single-phase beta. However, 1000 and 10,000 ppm oxygen produce microstructures in which the volume percentage of alpha increases from zero to 17 and 60 per cent, respectively. The importance of control and knowledge of alloy oxygen content for prediction of constitution is evident from the se values.

A projected use for these curves is the estimation of oxygen in zirconium-uranium alloys. Thus, on the basis of a heat treatment at $660 \mathrm{C}$ and a quantitative measurement of the phases present, an estimate of oxygen content is possible. Such an estimate should be fairly accurate in the higher uranium alloys but becomes more uncertain as uranium content decreases, since the variation in amount of alpha phase present becomes less sensitive to oxygen content.

During the course of these calculations, an equation for the tie lines connecting the alpha and beta phases in equilibrium was determined. The equation is given on page 21 . 


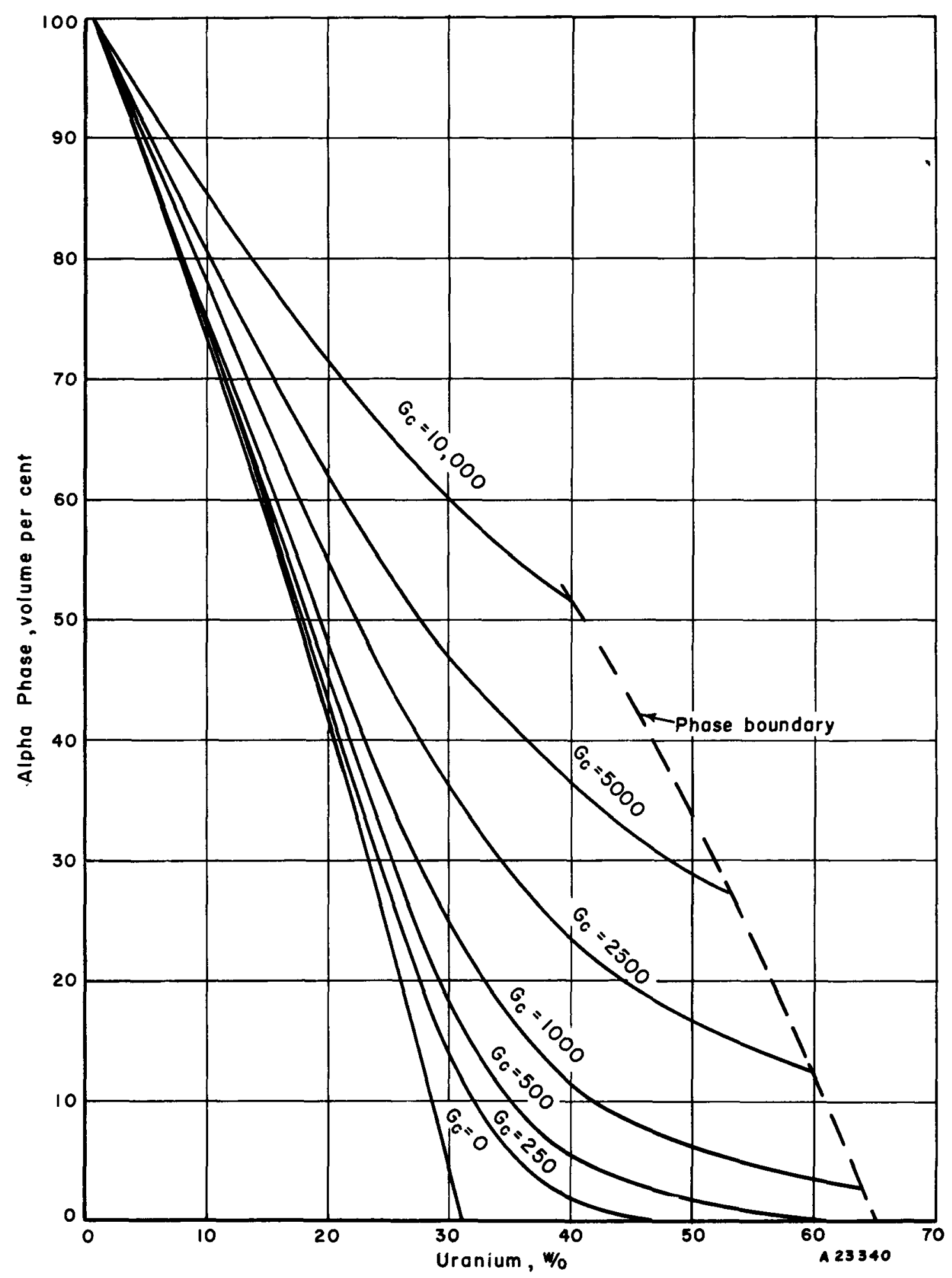

FIGURE 7. VOLUME PERCENTAGE OF ALPHA PHASE AS A FUNCTION OF OXYGEN AND URANIUM CONTENT IN ZIRCONIUM-URANIUM ALLOYS AT $660 \mathrm{C}$ 


$$
G_{C}=a+m U_{C}
$$

where

$\mathrm{U}_{\mathrm{A}}$

$$
\begin{gathered}
a=G_{A}-U_{A} \cdot \frac{\left(G_{A}-G_{B}\right)}{\left(U_{A}-U_{B}\right)} \\
m=\frac{\left(G_{A}-G_{B}\right)}{\left(U_{A}-U_{B}\right)} .
\end{gathered}
$$

\section{SUMMARY AND CONCLUSIONS}

Quantitative lineal data have been obtained on a series of zirconium-uranium alloys containing calculated additions of oxygen and nitrogen. From these data, the phase boundary between the beta and alpha-plus-beta-zirconium region of the zirconiumuranium ternary systems with oxygen and nitrogen has been determined. The calculated phase boundaries have been put in the form of an equation. Assumptions as to the geometry and limits of the phase region were required for the calculations; these have been stated.

Extrapolation of the data to zero oxygen content results in a calculated phase boundary at $660 \mathrm{C}$ of $31 \mathrm{w} / \mathrm{o}$ uranium in the binary zirconium-uranium system.

Maximum solubility of oxygen in the beta-zirconium phase occurs at a composition of $65 \mathrm{w} / \mathrm{o}$ uranium and is $556 \mathrm{ppm}$ oxygen. Maximum nitrogen solubility, $425 \mathrm{ppm}$, occurs at the same uranium composition. Oxygen and nitrogen contents of the alpha phases in equilibrium with these saturated beta-phase compositions are 25,020 and $19,125 \mathrm{ppm}$, respectively.

Upon the basis of these calculated values, revision of the zirconium-uranium and zirconium-uranium-oxygen constitutional diagrams is proposed. The revised partial diagrams are shown in Figures 8 and 9. The principal features of the proposed revisions are the slightly wider solubility range in the beta field with respect to zirconium content in the zirconium-uranium system and the more restricted alpha-plus-beta field in the ternary system with respect to oxygen content of the alpha phase.

A partial diagram for the zirconium-uranium-nitrogen system, Figure 10, is also proposed. This diagram is exactly similar to the previous ternary diagram with the exception of the more restricted solubility limits. 


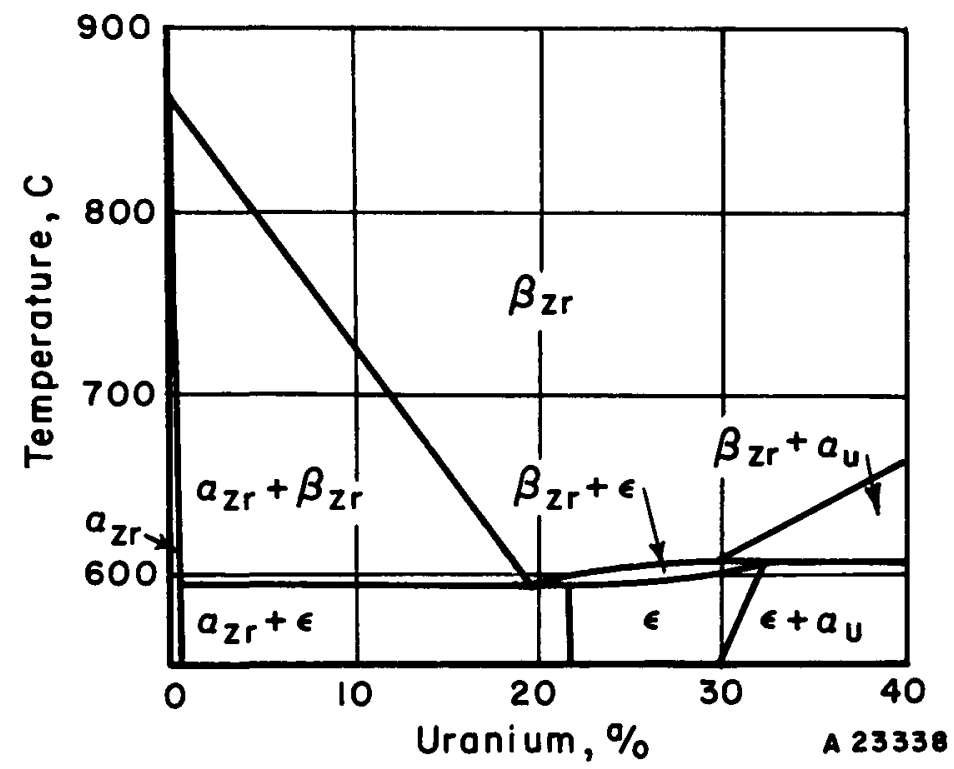

FIGURE 8. PROPOSED REVISION OF ZIRCONIUM-RICH PORTION OF ZIRCONIUM-URANIUM CONSTITUTIONAL DIAGRAM 


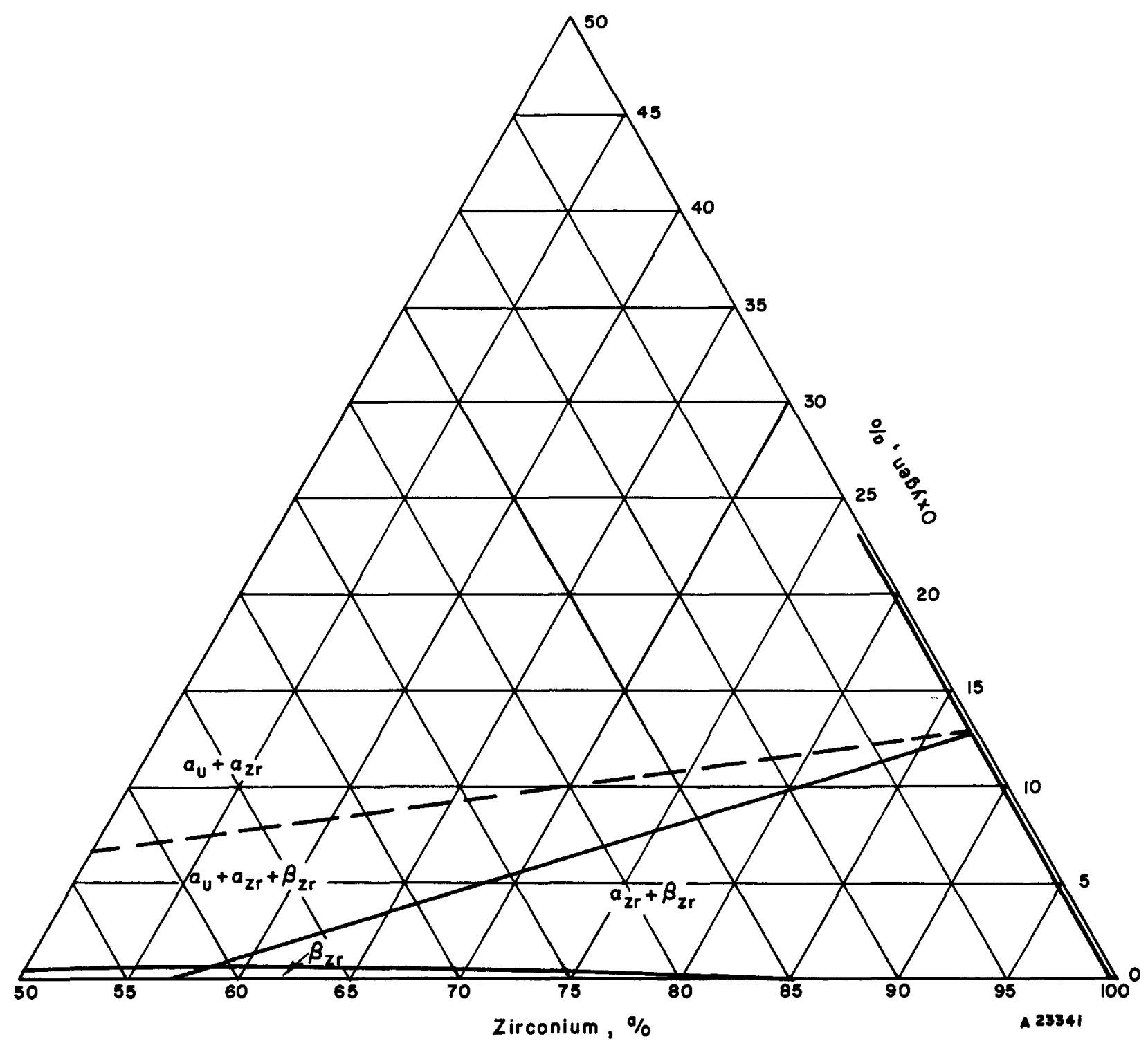

FIGURE 9. PROPOSED REVISION OF ZIRCONIUM CORNER OF ZIRCONIUMURANIUM-OXYGEN TERNARY DIAGRAM AT $660 \mathrm{C}$ 


\section{CONFIDENTIAL}

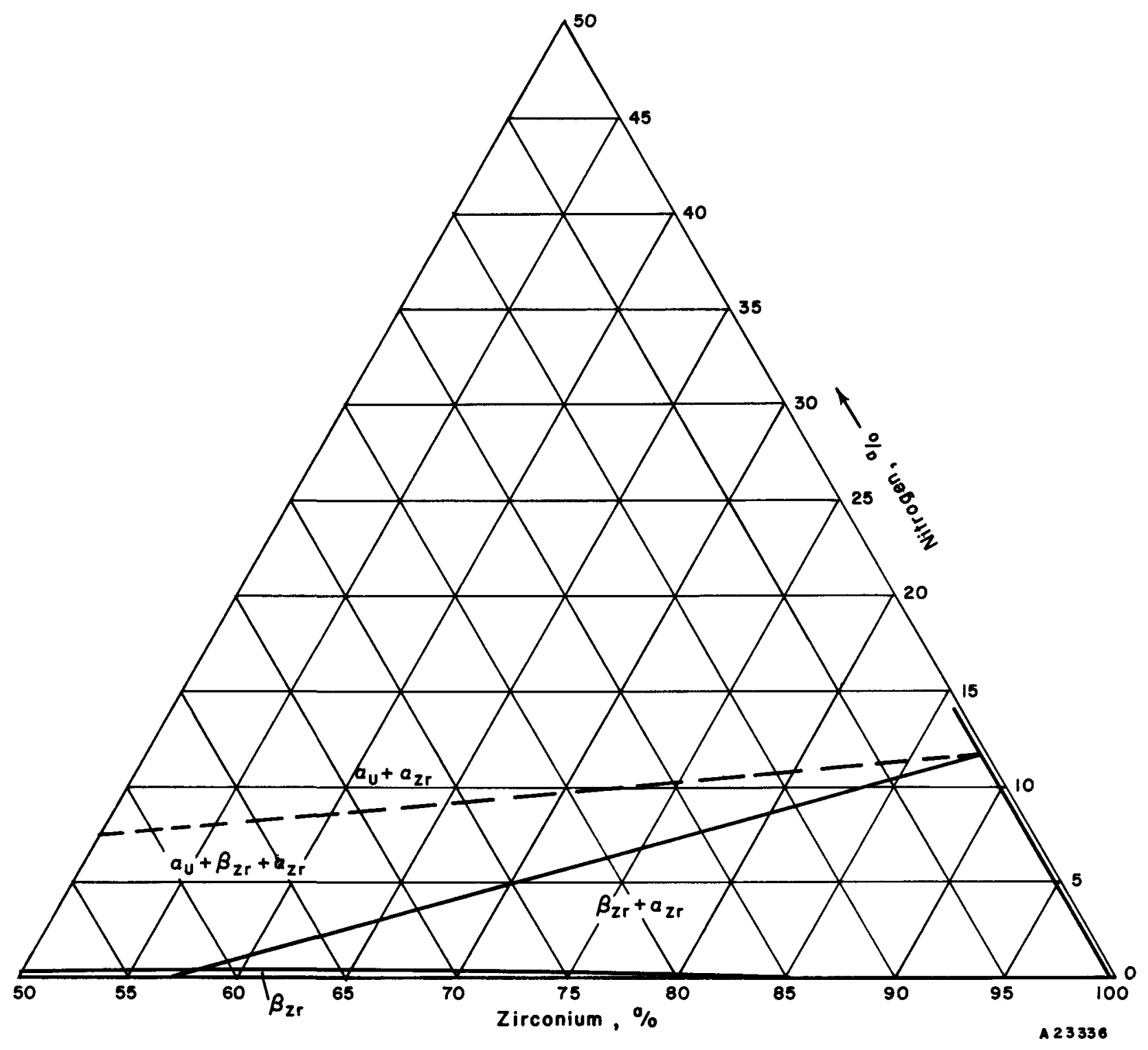

FIGURE 10. PROPOSED ZIRCONIUM CORNER OF ZIRCONIUM-URANIUMNITROGEN TERNARY DIAGRAM AT $660 \mathrm{C}$ 


\section{REFERENCES}

(1) Rough, F. A., Austin, A. E., Bauer, A. A., and Doig, J. R., "The Stability and Existence Range of the Zirconium-Uranium Epsilon Phase", BMI-1092 (May 28, 1956).

(2) Saller, H. A., Rough, F. A., Fackelmann, J. M., and Bauer, A. A., "Phase Relationships in the Uranium-Zirconium-Oxygen System Involving Zirconium and Uranium Dioxide", BMI-1023 (July 28, 1955).

(3) Saller, H. A., Rough, F. A., and Bauer, A. A., "The Effect of Oxygen on Zirconium-Uranium Epsilon Phase Alloys", Second Nuclear Engineering and Science Conference, Paper No. 57-NESC-20 (March 14, 1957).

(4) Metallurgy of Zirconium, NNES VII-4, McGraw Hill Book Company (1955), p 560.

(5) Bauer, A. A., unpublished information (1953).

AAB:GHB:FAR:RFD/ijs 